\title{
Cerebrospinal Fluid and Clinical Profiles in Adult Type 2-3 Spinal Muscular Atrophy Patients Treated with Nusinersen: An 18-Month Single-Centre Experience
}

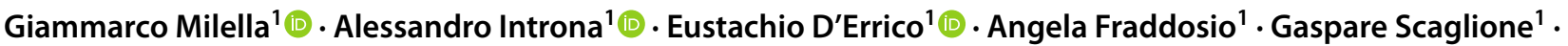 \\ Antonella Morea ${ }^{1} \cdot$ Maria Ucci $^{1} \cdot$ Maddalena Ruggieri $^{2}$ D $\cdot$ Mariangela Mastrapasqua $^{2} \cdot$ Marisa Megna $^{3}$. \\ Filomena Puntillo ${ }^{\mathbb{D}} \cdot$. Isabella Laura Simone ${ }^{1}$ (D)
}

Accepted: 27 July 2021 / Published online: 13 August 2021

(c) The Author(s) 2021

\begin{abstract}
Background and Objectives Nusinersen was approved as the first disease-modifying therapy in spinal muscular atrophy (SMA). Our aim was to analyse therapy-related changes in cerebrospinal fluid (CSF) and serum parameters of adult type 2-3 SMA and to correlate biochemical data with motor functional status.

Methods Nine adult SMA type 2-3 patients and ten control subjects without neurodegenerative diseases were included in our single-centre study. Cross-sectional analysis of CSF routine parameters, CSF neurofilament light chain, CSF Tau, CSF phospho-Tau and serum creatinine was performed between SMA patients at baseline (T0) and control subjects. The abovementioned fluid parameters were longitudinally analysed in the SMA cohort after loading dose (T1) and after four maintenance doses (T2, T3, T4, T5). Hammersmith Functional Motor Scale Expanded (HFMSE), Revised Upper Limb Module (RULM) and the 6-minute walking test (6MWT) were used to evaluate motor outcomes.

Results Improvements in HFMSE, RULM and 6MWT were observed only after the loading dose of nusinersen. No significant differences in routine CSF parameters and CSF markers of neurodegeneration were found between SMA patients and control subjects. Serum creatinine levels were significantly lower in SMA patients than in control subjects. CSF/serum albumin ratio (Qalb) significantly increased from T0 to each time point, without any further increase after the maintenance doses. Persistent systemic oligoclonal bands (OCBs) were found in five patients from baseline. Three more patients developed persistent systemic OCBs from T1; one patient showed intrathecal OCBSs from baseline to T5. Markers of neurodegeneration did not change during the follow-up and did not correlate with motor scores at baseline and at each timepoint. Serum creatinine levels significantly correlated with HFMSE and RULM at each time point.

Conclusions The increase of the Qalb values and the development of systemic OCBs in some SMA patients could be due to repeated lumbar puncture and to the immunogenic effect of nusinersen. On the other hand, the presence of OCBs in serum and/or CSF at baseline should be further investigated. Furthermore, biomarkers of neurodegeneration did not play a prognostic role in our cohort of adult SMA patients.
\end{abstract}

\section{Introduction}

Spinal muscular atrophy (SMA) is an autosomal, neurodegenerative disease caused by homozygous deletion or point mutation in gene survival motor neuron 1 (SMN1) on chromosome 5 , which results in a reduction of fully

Isabella Laura Simone

isabellalaura.simone@uniba.it

Extended author information available on the last page of the article functional SMN protein. The role of this protein is essential in neuronal and peripheral tissue development, and its absence leads prevalently to degeneration of lower motor neurons with progressive skeletal, bulbar and respiratory muscle weakness [1]. Most subjects retain the function of at least one copy of the paralogous gene SMN2, whose RNA transcripts could lead to the production of reduced levels of functional SMN protein, due to alternative splicing that excludes exon 7 of the protein SMN. A wide spectrum of clinical severity characterises the disease, which is classified according to age at onset and motor milestones achieved. 


\section{Key Points}

Nusinersen is the first disease-modifying therapy approved in spinal muscular atrophy. Robust biomarkers of treatment-response in adult SMA are still lacking.

In our cohort routine CSF parameters were normal except for blood-brain barrier dysfunction and systemic oligoclonal bands synthesis detected at the baseline and during treatment with nusinersen. Blood-brain barrier dysfunction and immunological impairment could reflect the systemic involvement beyond motor neurons that characterises SMA disease.

CSF neurofilament light chain, Tau and Ptau did not change during treatment with nusinersen.

The most severe phenotype is the type 0 SMA, with prenatal onset and death early after birth; the onset of type 1 SMA (namely Werdnig Hoffman syndrome) is within the first months of life and the death occurs within 2 years; type 2 and type 3 SMA (namely Kugelberg-Welander) usually display a highly variable phenotypic spectrum of disease, with life expectancy from infancy to adult age; finally type 4 SMA shows mild motor symptoms starting in the adult age with a very slow evolution over time [2]. The severity of the clinical phenotypes correlates inversely with the number of SMN2 copies, with $0-1$ copies of SMN2 in the most severe type 0 , or more than 4 copies in the mildest type 4 [1]. Nevertheless, this phenotype-genotype correlation is not absolute, as recent studies indicated that additional cellular mechanisms (e.g., positive or negative disease modifiers) may be involved in the modulation of SMA clinical severity [3,4]. The antisense oligonucleotide nusinersen is the first disease-modifying drug approved for the treatment of children and adult SMA patients [5]. It binds the SMN2 pre-mRNA downstream of exon 7, leading to the translation of a fully functional SMN protein [6]. Nusinersen must be intrathecally (i.t) administered, due to its inability to cross the blood-brain barrier (BBB). The central nervous system (CNS) tissue is the primary site of action for nusinersen, while the plasma is just a site for the clearance of the drug and, to date, no biologically active sites for nusinersen have been reported within peripheral tissues [7]. Considering the high cost of nusinersen, as well as the compliance of the patients because of the intrathecal administration, robust biomarkers of early treatment response are required to identify patients who could benefit from it. Although several studies showed the role of some cerebrospinal fluid (CSF) parameters as prognostic biomarkers in children with SMA type 1 treated with nusinersen [8-10], studies on late-onset
SMA patients provided less robust results on the role of CSF neurofilament light chain (NFL) and Tau, probably due to the wide range of age of onset, long disease duration and highly variable phenotypic spectrum of disease [11-13]. Recent studies proposed amyloid peptide 1-42 [14] and proteomics profile [15] as new promising biomarkers to evaluate treatment response in late-onset SMA patients.

We report a single-center study in a small cohort of adult SMA patients treated with nusinersen. The main aim was to gain further knowledge on changes in CSF and serum parameters during nusinersen treatment and to correlate biochemical data with clinical changes to find potential biomarkers of treatment response.

\section{Patients and Methods}

\subsection{Subjects}

SMA patients referring to the regional center of motor neuron diseases of the Department of Neurology at the University of Bari, Italy were included in the study. Patients were treated with nusinersen from October 2018 to January 2021. Inclusion criteria were: (1) age $\geq 18$ years at the time of enrollment; (2) molecular confirmation of SMA by genetic testing; (3) SMA type 2 or 3, without limitation with regard to the age of onset or initial diagnosis; (4) willingness to pursue clinical treatment with nusinersen; (5) willingness and ability to participate in outcome measure assessments. Patients were informed in detail about the lumbar puncture and the potential need for imaging, with CT-scan, with subsequent radiation exposure, due to spinal abnormalities. All patients gave written informed consent. The study was approved by the Interregional Independent Ethics Committee of Azienda Ospedaliero-Universitaria Policlinico Bari, Italy (N.6779).

Nusinersen was administered according to the standard protocol [16]. Before each intrathecal administration of 12 $\mathrm{mg} / 5 \mathrm{~mL}$ of the drug, $5 \mathrm{~mL}$ of CSF had been withdrawn at baseline (T0), at day 63 (T1) after the loading dose, and at each maintenance dose: day 180 (T2), day 300 (T3), day 420 (T4) and day 540 (T5).

Patients were functionally rated as walkers, sitters and non-sitters as described elsewhere [17]. Clinical severity was evaluated by Hammersmith Functional Motor Scale Expanded (HFMSE), which consists of 33 items with a maximum of 66 points (higher scores indicating better function), and Revised Upper Limb Module for SMA (RULM), which includes 20 items with a maximum score of 37 (higher scores indicating better function). Although a recent study has questioned the validity of these scales in adult SMA patients [18], they were the most widely used motor scales in multicentre observational cohort studies of adult SMA 
patients [13, 19-21]. Patients were defined as walkers if able to ambulate with or without walking aids and orthotics, for a distance $\geq 10 \mathrm{~m}[22]$. The clinical outcome measure for SMA patients able to walk was assessed using the 6-minute walking test (6MWT) [23]. Clinical evaluation was performed before the first administration (T0), at the loading dose (T1) and at each maintenance dose (T2, T3, T4, T5).

\subsection{Cerebrospinal Fluid (CSF) and Serum Samples}

CSF and serum samples were collected according to standardized procedures.

After collection, CSF routine analysis was immediately performed, including CSF cells count, CSF/serum glucose ratio and CSF/serum albumin ratio (Qalb). Normal Qalb values were considered as $<6.5$ for patients aged $18-40$ years, $<8.0$ for patients aged $41-60$ years and $<9.0$ for patients over 60 years of age [24, 25]. Accordingly, Qalb was defined as pathological for values greater than or equal to the reported thresholds. IgG oligoclonal bands in CSF or serum were qualitatively investigated by isoelectric focusing on polyacrylamide gel followed by immunoblotting using an IgG-specific antibody staining. Patterns of OCBs were classified according to an International Consensus [26]. Quantitative intrathecal IgG synthesis was performed by CSF/serum quotient diagram with plots according to Reiber [27] and also calculated by IgG Link index [24]. For the analysis of biomarkers of neurodegeneration as NFL, Tau and phosphor-Tau (p-Tau), an aliquot of CSF was immediately centrifuged within $30 \mathrm{~min}$ of the collection and subdivided into smaller polypropylene tubes. Considering the high susceptibility of NFL to degradation by proteases [28], a protease inhibitor (AEBSF-4-2-aminoethyl benzenesulfonyl fluoride hydrochloride Sigma-Aldrich, St. Louis, MO, USA) was added to CSF for NFL assay. All aliquots were stored at $-80^{\circ} \mathrm{C}$ until analysis. Commercially available ELISA kits were used for CSF NFL assay (ELISA test Uman Diagnostic AB; Umea, Sweden) (inter-assay variability coefficient $<9 \%$ ) as previously reported [29-31]. A solid-phase enzyme immunoassay (Fujirebio Innotest, Gent Belgium) was used for CSF Tau, p-Tau, (Intra-assay CV\% was $<5$, inter-assay $\mathrm{CV} \%$ was $<10$ ) [31-33].

Creatinine levels were measured in serum samples. Kidney function was systematically monitored with creatinineindependent methods: no changes in cystatin C-calculated glomerular filtration rate were observed under nusinersen treatment.

\subsection{Control Group}

The control group included 12 patients without neurodegenerative or inflammatory neurological diseases (seven chronic migraines, five diabetic neuropathies) who underwent spinal tap for CSF analysis included in their diagnostic workup. Routine blood tests and brain MRI were normal in all patients. Only one lumbar puncture was obtained from each patient. The control group was matched for sex and age with the SMA population (Table 1).

\subsection{Statistical Analysis}

Continuous variables were described as mean, standard deviation (SD), median and range. Categorical variables were described with relative frequencies.

The Mann-Whitney and Fisher's exact tests were assessed for comparisons between SMA patients and the control group; Wilcoxon matched-pairs signed-rank test was used for longitudinal studies in SMA patients. Correlations between categorical demographic variables, motor outcome measures, CSF and serum parameters were investigated by point-biserial correlation coefficient or Spearman's correlation as appropriate. Considering the exploratory aim of this study and the small sample size, statistical tests were not performed in each subgroup (e.g. sitter, nonsitter, walker). Significance was set at a level of $\alpha \leq 0.05$. Statistical analysis was performed with the software IBM SPSS Statistics 22.

\section{Results}

\subsection{Demographic and Clinical Features in Spinal Muscular Atrophy (SMA) Patients}

Nine adult patients with SMA were included in the study: three patients were SMA type 2 and six SMA type 3 . The genetic analysis detected three copies of SMN2 in seven patients and four copies in the remaining two. Demographic and clinical features are reported in Table 1. One SMA type 2 patient underwent spinal fusion surgery due to severe scoliosis. Two patients voluntarily dropped out during the follow-up: the first at $\mathrm{T} 2$ and the second one at $\mathrm{T} 3$.

Significant increases in both RULM and HFMSE were observed from $\mathrm{T} 0$ to each time point, respectively $\mathrm{T} 1(p$ $=0.026$ and $p=0.039)$, T2 $(p=0.026$ and $p=0.039)$, T3 $(p=0.027$ and $p=0.026), \mathrm{T} 4(p=0.048$ and $p=0.042)$ and T5 ( $p=0.048$ and $p=0.042$ ) (Fig. 1a, 1b) Conversely, no clinical improvements were found between intermediate time points (T1-T2, T2-T3, T3-T4 and T4-T5). In the two patients able to walk, 6MWT increased from baseline to $\mathrm{T} 1$ by $50 \mathrm{~m}$ in one patient and $5 \mathrm{~m}$ in the other one, and it remained stable at each other time point. 
Table 1 Clinical and demographic features in SMA patients and control subjects

\begin{tabular}{lll}
\hline Characteristic & SMA patients, $n=9$ & Control subjects, $n=12$ \\
\hline Age at treatment (years) & & $46.7 \pm 2.45(47 ; 42-50)^{\mathrm{a}}$ \\
$\quad$ Mean \pm SD (median; range) & $42.56 \pm 14.37(41 ; 18-72)^{\mathrm{a}}$ & - \\
Age at onset (years) & $6.89 \pm 5.93(3 ; 1-16)$ & $8 / 4^{\mathrm{b}}$ \\
$\quad$ Mean \pm SD (median; range) & $6 / 3^{\mathrm{b}}$ & $66.7 \%$ \\
Sex $(\mathrm{M} / \mathrm{F})$ & $66.7 \%$ & - \\
$\mathrm{M}(\%)$ & & - \\
Age at onset (years) & $6.89 \pm 5.93(3 ; 1-16)$ & - \\
Mean \pm SD (median; range) & $33 \% / 44 \% / 23 \%$ & - \\
Non sitters/Sitters/Walkers $(\%)$ & & - \\
Disease duration at treatment (years) & $35.89 \pm 14.85(36 ; 4-62)$ & - \\
Mean \pm SD (median; range) & & \\
HFMSE at baseline & $14.78 \pm 20.88(7 ; 0-61)$ & \\
Mean \pm SD (median; range) & & \\
RULM at baseline & $17.6 \pm 13.9(15 ; 0-37)$ & \\
Mean \pm SD (median; range) & & \\
\hline
\end{tabular}

SMA spinal muscular atrophy, HFMSE Hammersmith Functional Motor Scale Expanded, RULM Revised Upper Limb Module

${ }^{a}$ Mann-Whitney U test: $p=\mathrm{ns}$

${ }^{\mathrm{b}}$ Fisher's exact test $p=\mathrm{ns}$

\subsection{CSF and Serum Findings}

\subsubsection{Cross-Sectional Analysis Between SMA Patients and Control Subjects at Baseline}

At T0 CSF white cells and CSF/serum glucose ratio were within the normal range. No significant differences in Qalb values were found between SMA patients and control subjects $(p=0.602)$. One patient with SMA type 2 and two patients with SMA type 3 showed a BBB dysfunction, according to the above-mentioned cut-offs. Serum and corresponding CSF IgG oligoclonal bands (OCBs) (pattern 4) were found in four SMA patients, whereas intrathecal $\operatorname{IgG}$ OCBs associated with systemic OCBs (pattern 3) was found only in one SMA patient. In all control subjects, CSF and serum IgG pattern was normal. No differences in CSF NFL, Tau and p-Tau levels between SMA patients and the control group were found $(p=0.542, p=0.157, p=0.602$, respectively). Serum creatinine levels were lower in SMA patients compared to control subjects $(p<0.001)$.

\subsubsection{Longitudinal Analysis in SMA Patients}

Longitudinal CSF and serum parameters in SMA patients were reported in Table 2. No changes in CSF white cells and $\mathrm{CSF} /$ serum glucose ratio were detected in relation to treatment with nusinersen.

A significant increase of Qalb was observed from T0 to each time point, respectively T1 $(p=0.012), \mathrm{T} 2(p=0.007)$,
T3 $(p=0.012)$, T4 $(p=0.018)$ and T5 $(p=0.02)$, but not between intermediate time points (T1-T2, T2-T3, T3-T4 and T4-T5). Looking at Fig. 2, BBB dysfunction was confirmed after each administration of nusinersen in the three patients who exhibited this finding even at baseline, with an increase of Qalb values at T1 and T2 in one of them, and at $\mathrm{T} 3$ in the remaining two patients. One SMA 3 patient, with normal Qalb value at baseline, developed BBB damage from $\mathrm{T} 1$ to the drop out (T2). Of the remaining five patients with normal Qalb values at baseline, three patients showed a slight but not pathological increase of Qalb from T1 to T4. At the end of the follow-up, only three patients showed near-baseline values.

The pathological patterns of IgG OCBs found at the baseline in five patients did not change during the longitudinal evaluation. Moreover, three more patients developed persistent systemic OCBs from $\mathrm{T} 1$ to T5. IgG Link Index ranged from 0.4 to 0.5 in all SMA patients, without any significant changes during the follow-up.

No significant changes in CSF NFL, CSF Tau and CSF p-Tau and serum creatinine levels were detected during nusinersen treatment.

\subsubsection{Correlation}

CSF routine parameters and markers of neurodegeneration did not correlate with sex, age and disease duration and motor scales (see Online Supplementary Material (OSM) Tables S1 and S2). Interestingly, serum creatinine levels 

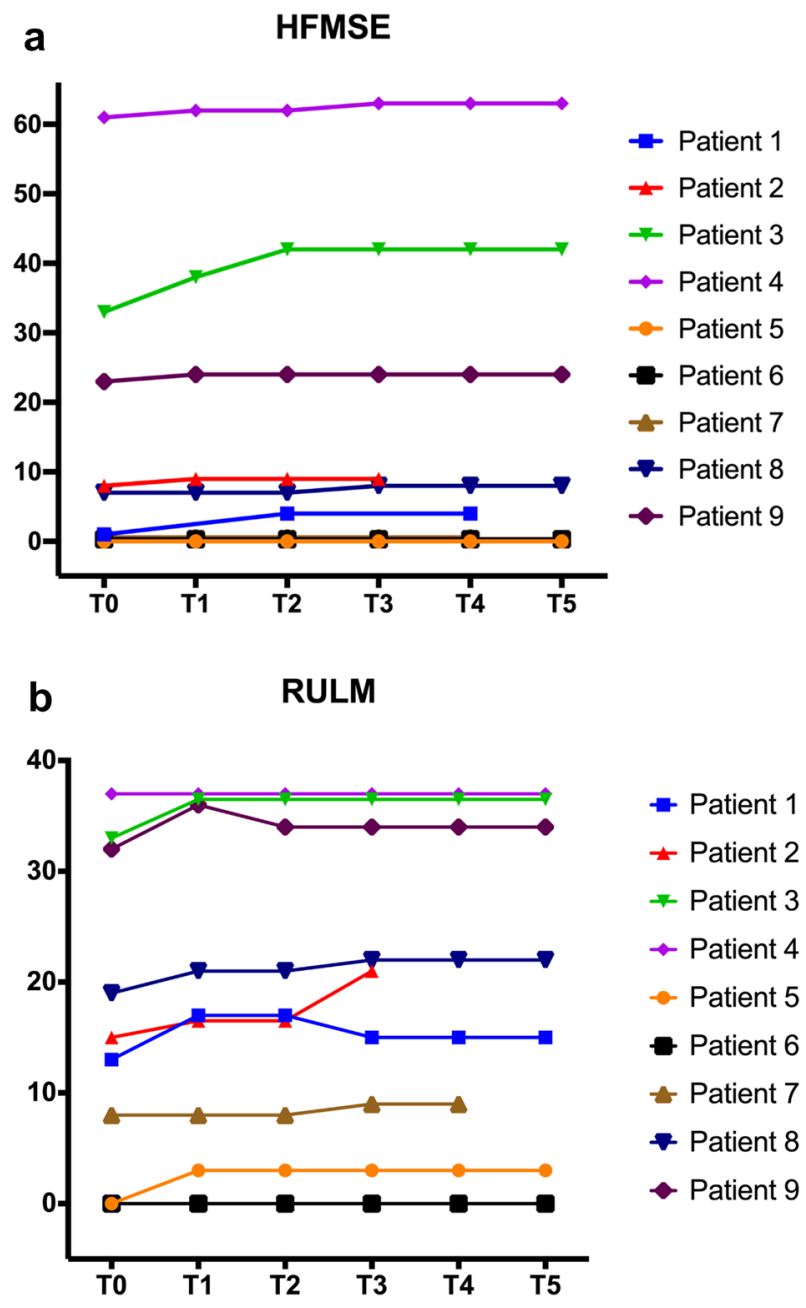

Fig. 1 a Longitudinal values of Hammersmith Functional Motor Scale Expanded (HFMSE). b Longitudinal values of Revised Upper Limb Module (RULM)

correlated with HFMSE (Spearman's correlation coefficient $\left.r_{\mathrm{s}}=0.702 ; p=0.035\right)$ and RULM $\left(r_{\mathrm{s}}=0.799 ; p=\right.$ $0.001)$ both at baseline and at each time point $(p<0.05$ with a $r_{\mathrm{s}}$ ranging from 0.707 to 0.827 regarding HFMSE and from 0.752 to 0.836 regarding RULM) (see OSM Table S2). Changes in motor scales between $\mathrm{T} 0$ and each time point did not correlate with changes in CSF biomarker of neurodegeneration and serum creatinine (see OSM Table S3).

\section{Discussion}

In our small cohort of adult SMA patients, clinical motor improvements were found only after the loading dose of nusinersen. As opposed to previous studies [20, 34], we failed to detect further clinical ameliorations during the maintenance doses, which could be related to several issues. First, the small sample size of our cohort, which, moreover, was phenotypically heterogenous, could have reduced the power of our statistical analysis. On the other hand, the motor scales used may have underestimated the clinical improvements in weaker patients ('floor effect') and stronger patients ('ceiling effect'), as suggested by VázquezCosta et al. [18]. Therefore, new outcome measures should probably be developed and/or validated in a larger cohort of adult SMA patients or at least different motor scales should be used after stratifying patients according to the functional subgroups (non-sitters, sitters, walkers) [18]. Nevertheless, albeit minimal, in our patients the clinical improvement remained stable after 18 months of follow-up.

The main results of the present study were the abnormalities found in CSF and serum parameters of adult SMA patients both at baseline and during nusinersen treatment. Focusing on Qalb, the BBB damage was already detected in three SMA patients at baseline. As reported in previous studies $[35,36]$, this finding might reflect a CSF flow dysfunction related to spinal stenosis or scoliosis, commonly found in patients with SMA. More interestingly, we found a slight but significant increase of Qalb already detectable after the loading dose of nusinersen in seven out of nine patients, independently from the baseline value. As suggested by previous studies [35, 36], this finding may be explained by the repeated lumbar punctures. We agree with previous studies that suggested routinely monitoring albumin CSF/serum ratio as a security marker of CSF flow dysfunction at each administration of nusinersen [12, 35].

Another interesting finding in our adult SMA patients was the evidence of an immunological involvement. Five patients showed the presence of systemic OCBs and one of them had associated intrathecal OCBs, already present at baseline. Wurster et al. reported the presence of intrathecal OCBs at baseline in only two out of 63 SMA patients, while systemic OCBs were not found [35]. On the contrary, systemic OCBs were detected at baseline in one out of 10 SMA patients [15]. The multi-system nature of SMA pathogenesis has been demonstrated in several previous studies [37, 38]. Specifically, immunological abnormalities have been observed in the spleens of patients and mouse models of SMA, including reduced size and number of lymphocytes, and increased levels of megakaryocytes [39]. Simultaneous systemic inflammation has been noted in a severe SMA mouse model with increased expression of proinflammatory cytokines in all tissues and activation of the proteins of acute phase response in the liver [40, 41]. Although the presence of systemic OCBs is a non-specific and ambiguous finding, it reflects the occurrence of a humoral response towards hetero- or autoantigens [42]. For the first time, the intrathecal administration of nusinersen in SMA provides the opportunity to explore biological compartments otherwise not investigated, since the diagnosis is prevalently based on genetic testing, the collection of data in larger case 
Table 2 CSF and serum findings in SMA patients (from baseline to each time point) and control subjects

\begin{tabular}{|c|c|c|c|c|c|c|c|c|}
\hline Subject group & $\begin{array}{l}\text { White cells/ } \mu \mathrm{L} \\
\text { (median; } \\
\text { range) }\end{array}$ & $\begin{array}{l}\mathrm{Q}_{\mathrm{alb}} \\
\text { mean } \pm \mathrm{SD} \\
\text { (median; } \\
\text { range) } \\
\text { [n. patients } \\
\text { with BBB } \\
\text { dysfunction] }\end{array}$ & $\begin{array}{l}\text { Systemic } \\
\text { OCB } \\
n \cdot \text { patients }\end{array}$ & $\begin{array}{l}\text { Intrathecal } \\
\text { OCB } \\
n \text {. patients }\end{array}$ & $\begin{array}{l}\text { CSF NFL, } \\
\mathrm{pg} / \mathrm{ml} \\
\text { mean } \pm \mathrm{SD} \\
\text { (median; } \\
\text { range) }\end{array}$ & $\begin{array}{l}\text { CSF Tau,pg/ } \\
\text { ml } \\
\text { mean } \pm \mathrm{SD} \\
\text { (median; } \\
\text { range) }\end{array}$ & $\begin{array}{l}\text { CSF p-Tau, } \\
\mathrm{pg} / \mathrm{ml} \\
\text { mean } \pm \mathrm{SD} \\
\text { (median; } \\
\text { range) }\end{array}$ & $\begin{array}{l}\text { Serum creati- } \\
\text { nine, } \mathrm{mg} / \mathrm{dl} \\
\text { mean } \pm \mathrm{SD} \\
\text { (median; range) }\end{array}$ \\
\hline $\begin{array}{l}\text { SMA patients } \\
\text { T0 (9) }\end{array}$ & $\begin{array}{l}1 \\
(0-4)\end{array}$ & $\begin{array}{l}5.5 \pm 2.5 \\
(4 ; 3.3-10.1) \\
{[n .3]}\end{array}$ & n. 4 & n. 1 & $\begin{array}{l}501.38 \pm \\
116.40 \\
(486 ; \\
343-695)\end{array}$ & $\begin{array}{l}176.1 \pm 78.4 \\
(189.5 ; \\
70-276)\end{array}$ & $\begin{array}{l}34.5 \pm 16.3 \\
(40 ; 16-57)\end{array}$ & $\begin{array}{l}0.22 \pm 0.08 \\
(0.18 \\
0.14-0.41)\end{array}$ \\
\hline $\begin{array}{l}\text { SMA patients } \\
\text { T1 (9) }\end{array}$ & $\begin{array}{l}1 \\
(0-2)\end{array}$ & $\begin{array}{l}6.5 \pm 2.9 \\
(4.6 ; 3.4-10.5) \\
{[n .4]}\end{array}$ & n. 7 & n. 1 & $\begin{array}{l}512.25 \pm \\
153.76 \\
(540 ; \\
317-813)\end{array}$ & $\begin{array}{l}166.5 \pm 84.4 \\
(144 ; 73-276)\end{array}$ & $\begin{array}{l}37.8 \pm 20.1 \\
(33.5 ; 16-64)\end{array}$ & $\begin{array}{l}0.24 \pm 0.11 \\
(0.17 \\
\quad 0.14-0.41)\end{array}$ \\
\hline $\begin{array}{l}\text { SMA patients } \\
\text { T2 (9) }\end{array}$ & $\begin{array}{l}1 \\
(0-3)\end{array}$ & $\begin{array}{l}6.9 \pm 3.2 \\
(5.6 ; 4-11.3) \\
{[n .4]}\end{array}$ & n. 7 & n. 1 & $\begin{array}{l}417.88 \pm \\
128.97 \\
(420 ; \\
185-601)\end{array}$ & $\begin{array}{l}167.6 \pm 90.4 \\
(173 ; 68-305)\end{array}$ & $\begin{array}{l}31.9 \pm 13.5 \\
(33 ; 16-57)\end{array}$ & $\begin{array}{l}0.24 \pm 0.15 \\
(0.17 \\
\quad 0.14-0.61)\end{array}$ \\
\hline $\begin{array}{l}\text { SMA patients } \\
\text { T3 (8) }\end{array}$ & $\begin{array}{l}1 \\
(0-2)\end{array}$ & $\begin{array}{l}7.1 \pm 3.2 \\
(5.6 ; 3.9-11.7) \\
{[n .3]^{\mathrm{a}}}\end{array}$ & $n .7$ & n. 1 & $\begin{array}{l}446.26 \pm \\
227.72 \\
(393.6 ; \\
192-920)\end{array}$ & $\begin{array}{l}165.7 \pm 73.9 \\
(171.5 ; \\
81-264)\end{array}$ & $\begin{array}{l}31.6 \pm 19.4 \\
(25 ; 16-64)\end{array}$ & $\begin{array}{l}0.29 \pm 0.17 \\
(0.24 ; \\
0.15-0.66)\end{array}$ \\
\hline $\begin{array}{l}\text { SMA patients } \\
\text { T4 (7) }\end{array}$ & $\begin{array}{l}2 \\
(1-4)\end{array}$ & $\begin{array}{l}6.6 \pm 2.8 \\
(5.6 ; 4-12.1) \\
{[n .2]^{\mathrm{b}}}\end{array}$ & n. $6^{\mathrm{c}}$ & n. 1 & $\begin{array}{l}423 \pm 152 \\
(457 ; \\
218-644)\end{array}$ & $\begin{array}{l}177.3 \pm 59.9 \\
(179 ; 84-240)\end{array}$ & $\begin{array}{l}37.7 \pm 12.2 \\
(43 ; 16-48)\end{array}$ & $\begin{array}{l}0.25 \pm 0.16 \\
(0.18 \\
\quad 0.14-0.57)\end{array}$ \\
\hline $\begin{array}{l}\text { SMA patients } \\
\text { T5 (7) }\end{array}$ & $\begin{array}{l}1 \\
(0-3)\end{array}$ & $\begin{array}{l}6.2 \pm 3.45 \\
(4.9 ; 3.4-13.1) \\
{[n .2]^{\mathrm{b}}}\end{array}$ & n. $6^{\mathrm{c}}$ & n. 1 & $\begin{array}{l}440 \pm 252 \\
(361 ; \\
160-957)\end{array}$ & $\begin{array}{l}151.6 \pm 53.3 \\
(158 ; 67-218)\end{array}$ & $\begin{array}{l}39.3 \pm 14 \\
(42 ; 16-53)\end{array}$ & $\begin{array}{l}0.24 \pm 0.17 \\
(0.18 ; \\
\quad 0.15-0.55)\end{array}$ \\
\hline $\begin{array}{l}\text { Control sub- } \\
\text { jects } \\
\text { (12) }\end{array}$ & $\begin{array}{l}1 ; \\
(0-2)\end{array}$ & $\begin{array}{l}5.9 \pm 2.3 \\
(5.6 ; 3.2-10.4) \\
{[\mathrm{s} n .2]}\end{array}$ & n. 0 & n. 0 & $\begin{array}{l}481.58 \pm 90 \\
(434.5 ; \\
385-628)\end{array}$ & $\begin{array}{l}125.8 \pm 56.9 \\
(120 ; 53-229)\end{array}$ & $\begin{array}{l}33.5 \pm 14.4 \\
(33 ; 15-58)\end{array}$ & $\begin{array}{l}0.88 \pm 0.15 \\
(0,94 ; \\
0,59-1,05)\end{array}$ \\
\hline
\end{tabular}

$S M A$ spinal muscular atrophy, $C S F$ cerebrospinal fluid, $Q_{a l b}$ CSF/serum albumin ratio, $B B B$ blood-brain-barrier, $O C B$ oligoclonal bands, $N F L$ neurofilament light chain, $p$-Tau phospho-Tau

${ }^{\mathrm{a}}$ One out of four patients with BBB dysfunction dropped out

${ }^{\mathrm{b}}$ Two out of four patients with BBB dysfunction dropped out

${ }^{c}$ One patient with systemic oligoclonal bands dropped out

series from multicentre studies could allow us to understand if some findings, such as the presence of OCB, are linked to the pathogenesis of the disease, or instead to a case. Undoubtedly, gathering data in larger case series from multicentre studies could allow us to understand whether some findings, such as the presence of OCBs, are related to the pathogenesis of the disease, or to chance. More interestingly, we found the development of systemic OCBs during treatment in three more patients. Previous studies reported the occurrence of transient positive OCBs in CSF during treatment with nusinersen and the authors speculated that this finding could be due to the immunogenic role of ASOs [15, 35]. On the other hand, two studies described unusual inclusions in CSF macrophages called 'nusinophages'. Gingele et al. [43] hypothesized that these granular inclusions could contain nusinersen, while Miranda et al. [44] suggested that the vacuoles and inclusions are due to macrophage activation and cytokine accumulation. Immunostimulatory effects have been previously associated with a large number of ASOs through different mechanisms: the base-pair sequence and the backbone chemistry of these drugs are recognized by nucleic acid-sensing TLR receptors inducing a drug-specific immune response [45]; moreover, ASOs directly act on lymphoid cells causing them to produce proinflammatory cytokines, such as TNF- $\alpha$ and interferon- $\gamma$, and consequently, IgG and IgM against auto- and hetero-antigens [46]. Based on this evidences, we could speculate that systemic OCBs developing during nusinersen treatment reflects antidrug antibody (ADA) production [47], or it could mirror the proinflammatory effects of this drug on immune system [46]. To explain the action of immune system in SMA, the future direction should be to characterize the IgG OCBs bands during nusinersen treatment, to investigate other markers of systemic immune activation, and to identify the possible 


\section{Qalb}

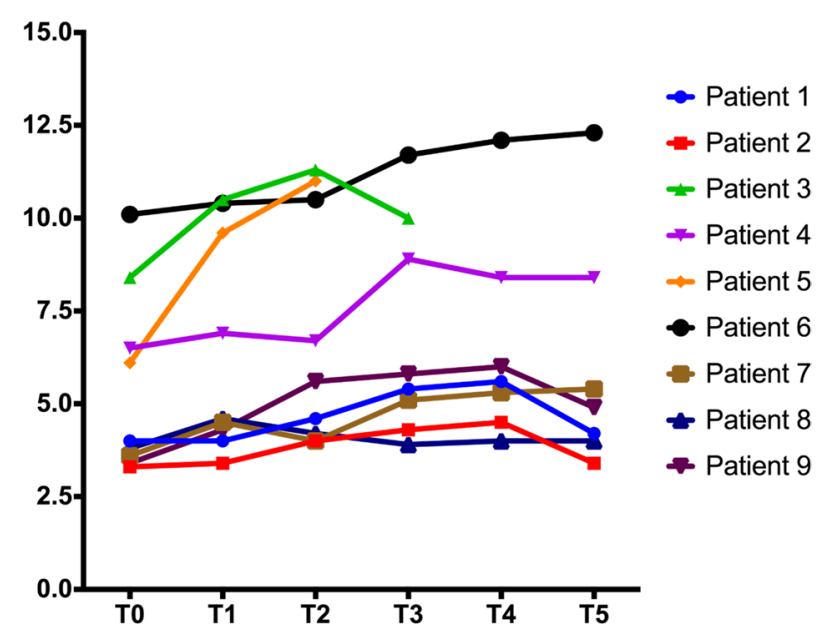

Fig. 2 Longitudinal values of the cerebrospinal fluid/serum albumin ratio

development of ADA that could influence the efficacy of nusinersen.

This study does not provide evidence of any sensitive and specific CSF biomarker of efficacy of nusinersen in our cohort. Similar to previous studies carried out in adult SMA patients, NFL, Tau and p-Tau in the CSF were similar to age-matched controls [11, 12]. In our adult SMA cohort we did not found changes in biomarkers, probably because the analysis has already been performed when the neurodegeneration process is completed, different to in paediatric SMA where this is ongoing [8, 9]. Furthermore, levels of CSF biomarkers did not change in relation to treatment with nusinersen or correlated with changes in motor scales. Again, this is in contrast to paediatric SMA patients, where the decrease of CSF NFL and Tau was more rapid under nusinersen therapy [8] and correlated with improvements in motor function [9]. These latter findings led to the proposal of the above-mentioned CSF parameters as potential biomarkers of treatment response in children with SMA type 1-2. To date, only two studies in adult SMA patients found a significant decrease of markers of neurodegeneration during nusinersen treatment [11, 34]. The longer disease duration (35.89 years compared to 20 [11] and 19.75 [34]) and the worse motor functional status of our cohort could explain the discrepancy with the reported studies.

In line with recent literature data [48], serum creatinine levels were remarkably lower in SMA patients compared to control subjects, and correlated with the disease duration and motor clinical scales, confirming the role of this serum parameter as biomarkers of disease severity. However, our study failed to find changes in serum creatinine levels in relation to nusinersen treatment. The lack of longitudinal changes in creatinine levels may depend on the small sample size as well as the short follow-up of our cohort to detect increases in serum creatinine levels since it reflects an amelioration of muscle mass. Additionally, it needs to be taken into account that serum creatinine levels could be influenced by several variables such as body mass index and hydration status. Future studies should evaluate the role of this serum biomarker in a prospective design after correcting creatinine levels for all known influencing factors.

Although noteworthy, our study is not without limitations: Considering the low prevalence of adult SMA patients eligible for nusinersen treatment, the monocentric nature of our study led to the enrolment of a limited number of patients. Larger multicentre patient cohorts are needed to confirm our findings.

\section{Conclusion}

Our study suggested that the development of BBB dysfunction and both systemic and intrathecal OCBs in some SMA patients could be due to repeated lumbar puncture and the immunogenic effect of nusinersen. Furthermore, biomarkers of neurodegeneration did not play a prognostic role in our cohort of adult SMA patients.

Supplementary Information The online version contains supplementary material available at https://doi.org/10.1007/s40261-021-01071-0.

Acknowledgements We are grateful to the SMA patients and their families. We would like to thank all the healthcare personnel involved with the nusinersen administration.

\section{Declarations}

Funding No funding was received for conducting this study. Open access funding provided by Università degli Studi di Bari Aldo Moro within the CRUI-CARE Agreement.

Conflict of interest The authors declare that they have no competing interests.

Ethics approval We confirm that we have read the Journal's position on issues involved in ethical publication and affirm that this report is consistent with those guidelines. Ethical approval was waived by the local Ethics Committee considering that all the procedures being performed were part of the routine care.

Consent to participate All patients gave written informed consent to be enrolled in the study.

Consent for publication N/A.

Availability of data and material The data that support the findings of this study are available from the corresponding author upon reasonable request.

Code availability N/A. 
Open Access This article is licensed under a Creative Commons Attribution-NonCommercial 4.0 International License, which permits any non-commercial use, sharing, adaptation, distribution and reproduction in any medium or format, as long as you give appropriate credit to the original author(s) and the source, provide a link to the Creative Commons licence, and indicate if changes were made. The images or other third party material in this article are included in the article's Creative Commons licence, unless indicated otherwise in a credit line to the material. If material is not included in the article's Creative Commons licence and your intended use is not permitted by statutory regulation or exceeds the permitted use, you will need to obtain permission directly from the copyright holder. To view a copy of this licence, visit $\mathrm{http} / / /$ creativecommons.org/licenses/by-nc/4.0/.

\section{References}

1. Darras BT. Spinal muscular atrophies. Pediatr Clin N Am. 2015;62:743-66. https://doi.org/10.1016/j.pcl.2015.03.010.

2. Kolb SJ, Coffey CS, Yankey JW, Krosschell K, Arnold WD, Rutkove SB, Swoboda KJ, Reyna SP, Sakonju A, Darras BT, et al. Natural history of infantile-onset spinal muscular atrophy. Ann Neurol. 2017;82:883-91. https://doi.org/10.1002/ana.25101.

3. Prior TW, Krainer AR, Hua Y, Swoboda KJ, Snyder PC, Bridgeman SJ, Burghes AHM, Kissel JT. A positive modifier of spinal muscular atrophy in the SMN2 gene. Am J Hum Genet. 2009;85:408-13. https://doi.org/10.1016/j.ajhg.2009.08.002.

4. Cuscó I, Bernal S, Blasco-Pérez L, Calucho M, Alias L, FuentesPrior P, Tizzano EF. Practical guidelines to manage discordant situations of SMN2 copy number in patients with spinal muscular atrophy. Neurol Genet. 2020;6: e530. https://doi.org/10.1212/ NXG.0000000000000530.

5. Mercuri E, Darras BT, Chiriboga CA, Day JW, Campbell C, Connolly AM, Iannaccone ST, Kirschner J, Kuntz NL, Saito K, et al. Nusinersen versus sham control in later-onset spinal muscular atrophy. N Engl J Med. 2018;378:625-35. https://doi.org/10.1056/ NEJMoa1710504.

6. Finkel RS, Chiriboga CA, Vajsar J, Day JW, Montes J, De Vivo DC, Yamashita M, Rigo F, Hung G, Schneider E, et al. Treatment of infantile-onset spinal muscular atrophy with nusinersen: a phase 2, open-label, dose-escalation study. Lancet Lond Engl. 2016;388:3017-26. https://doi.org/10.1016/S0140-6736(16) 31408-8.

7. Luu KT, Norris DA, Gunawan R, Henry S, Geary R, Wang Y. Population pharmacokinetics of nusinersen in the cerebral spinal fluid and plasma of pediatric patients with spinal muscular atrophy following intrathecal administrations. J Clin Pharmacol. 2017;57:1031-41. https://doi.org/10.1002/jcph.884.

8. Winter B, Guenther R, Ludolph AC, Hermann A, Otto M, Wurster CD. Neurofilaments and Tau in CSF in an infant with SMA type 1 treated with nusinersen. J Neurol Neurosurg Psychiatry. 2019;90:1068-9. https://doi.org/10.1136/jnnp-2018-320033.

9. Olsson B, Alberg L, Cullen NC, Michael E, Wahlgren L, Kroksmark A-K, Rostasy K, Blennow K, Zetterberg H, Tulinius M. NFL is a marker of treatment response in children with SMA treated with nusinersen. J Neurol. 2019;266:2129-36. https://doi.org/10. 1007/s00415-019-09389-8.

10. Darras BT, Crawford TO, Finkel RS, Mercuri E, De Vivo DC, Oskoui M, Tizzano EF, Ryan MM, Muntoni F, Zhao G, et al. Neurofilament as a potential biomarker for spinal muscular atrophy. Ann Clin Transl Neurol. 2019;6:932-44. https://doi.org/10.1002/acn3.779.

11. Faravelli I, Meneri M, Saccomanno D, Velardo D, Abati E, Gagliardi D, Parente V, Petrozzi L, Ronchi D, Stocchetti N, et al. Nusinersen treatment and cerebrospinal fluid neurofilaments: an explorative study on spinal muscular atrophy type 3 patients. J Cell Mol Med. 2020;24:3034-9. https://doi.org/10.1111/jcmm. 14939.

12. Wurster CD, Günther R, Steinacker P, Dreyhaupt J, Wollinsky K, Uzelac Z, Witzel S, Kocak T, Winter B, Koch JC, et al. Neurochemical markers in CSF of adolescent and adult SMA patients undergoing nusinersen treatment. Ther Adv Neurol Disord. 2019;12:1756286419846058. https://doi.org/10.1177/1756286419 846058.

13. Totzeck A, Stolte B, Kizina K, Bolz S, Schlag M, Thimm A, Kleinschnitz C, Hagenacker T. Neurofilament heavy chain and tau protein are not elevated in cerebrospinal fluid of adult patients with spinal muscular atrophy during loading with nusinersen. Int J Mol Sci. 2019. https://doi.org/10.3390/ijms20215397.

14. Introna A, Milella G, D'Errico E, Fraddosio A, Scaglione G, Ucci M, Ruggieri M, Simone IL. Is cerebrospinal fluid amyloid-B42 a promising biomarker of response to nusinersen in adult spinal muscular atrophy patients? Muscle Nerve. 2021. https://doi.org/ 10.1002/mus.27212.

15. Kessler T, Latzer P, Schmid D, Warnken U, Saffari A, Ziegler A, Kollmer J, Möhlenbruch M, Ulfert C, Herweh C, et al. Cerebrospinal fluid proteomic profiling in nusinersen-treated patients with spinal muscular atrophy. J Neurochem. 2020;153:650-61. https:// doi.org/10.1111/jnc.14953.

16. https://www.ema.europa.eu/en/medicines/human/EPAR/spinraza. Accessed 23 Jul 2021.

17. Mercuri E, Finkel RS, Muntoni F, Wirth B, Montes J, Main M, Mazzone ES, Vitale M, Snyder B, Quijano-Roy S, et al. Diagnosis and management of spinal muscular atrophy: part 1: recommendations for diagnosis, rehabilitation, orthopedic and nutritional care. Neuromuscul Disord NMD. 2018;28:103-15. https://doi.org/10. 1016/j.nmd.2017.11.005.

18. Vázquez-Costa JF, Povedano M, Nascimiento-Osorio AE, Escribano AM, Garcia SK, Dominguez R, Exposito JM, González L, Marco C, Castillo JM, et al. Validation of motor and functional scales for the evaluation of adult patients with $5 \mathrm{q}$ spinal muscular atrophy. medRxiv. 2021. https://doi.org/10.1101/2021.06.12. 21258357.

19. Hagenacker T, Wurster CD, Günther R, Schreiber-Katz O, Osmanovic A, Petri S, Weiler M, Ziegler A, Kuttler J, Koch JC, et al. Nusinersen in adults with $5 q$ spinal muscular atrophy: a noninterventional, multicentre, observational cohort study. Lancet Neurol. 2020;19:317-25. https://doi.org/10.1016/S1474-4422(20) 30037-5.

20. Maggi L, Bello L, Bonanno S, Govoni A, Caponnetto C, Passamano L, Grandis M, Trojsi F, Cerri F, Ferraro M, et al. Nusinersen safety and effects on motor function in adult spinal muscular atrophy type 2 and 3. J Neurol Neurosurg Psychiatry. 2020;91:116674. https://doi.org/10.1136/jnnp-2020-323822.

21. Yeo CJJ, Simeone SD, Townsend EL, Zhang RZ, Swoboda KJ. Prospective cohort study of nusinersen treatment in adults with spinal muscular atrophy. J Neuromuscul Dis. 2020;7:257-68. https://doi.org/10.3233/JND-190453.

22. Morganti B, Scivoletto G, Ditunno P, Ditunno JF, Molinari M. Walking index for spinal cord injury (WISCI): criterion validation. Spinal Cord. 2005;43:27-33. https://doi.org/10.1038/sj.sc. 3101658.

23. Dunaway Young S, Montes J, Kramer SS, Marra J, Salazar R, Cruz R, Chiriboga CA, Garber CE, De Vivo DC. Six-minute walk test is reliable and valid in spinal muscular atrophy. Muscle Nerve. 2016;54:836-42. https://doi.org/10.1002/mus.25120.

24. Tibbling G, Link H, Ohman S. Principles of Albumin and IgG Analyses in Neurological Disorders. I. Establishment of Reference Values. Scand J Clin Lab Invest. 1977;37:385-90. https://doi.org/ 10.1080/00365517709091496. 
25. Reiber H. External quality assessment in clinical neurochemistry: survey of analysis for cerebrospinal fluid (CSF) proteins based on CSF/serum quotients. Clin Chem. 1995;41:256-63.

26. Andersson M, Alvarez-Cermeño J, Bernardi G, Cogato I, Fredman P, Frederiksen J, Fredrikson S, Gallo P, Grimaldi LM, Grønning M. Cerebrospinal fluid in the diagnosis of multiple sclerosis: a consensus report. J Neurol Neurosurg Psychiatry. 1994;57:897902. https://doi.org/10.1136/jnnp.57.8.897.

27. Reiber H. Cerebrospinal fluid-physiology, analysis and interpretation of protein patterns for diagnosis of neurological diseases. Mult Scler Houndmills Basingstoke Engl. 1998;4:99-107. https:// doi.org/10.1177/135245859800400302.

28. Goldstein ME, Sternberger NH, Sternberger LA. Phosphorylation protects neurofilaments against proteolysis. J Neuroimmunol. 1987;14:149-60. https://doi.org/10.1016/0165-5728(87)90049-x.

29. Tortelli R, Ruggieri M, Cortese R, D’Errico E, Capozzo R, Leo A, Mastrapasqua M, Zoccolella S, Leante R, Livrea P, et al. Elevated cerebrospinal fluid neurofilament light levels in patients with amyotrophic lateral sclerosis: a possible marker of disease severity and progression. Eur J Neurol. 2012;19:1561-7. https:// doi.org/10.1111/j.1468-1331.2012.03777.x.

30. Petzold A, Altintas A, Andreoni L, Bartos A, Berthele A, Blankenstein MA, Buee L, Castellazzi M, Cepok S, Comabella M, et al. Neurofilament ELISA validation. J Immunol Methods. 2010;352:23-31. https://doi.org/10.1016/j.jim.2009.09.014.

31. Scarafino A, D'Errico E, Introna A, Fraddosio A, Distaso E, Tempesta I, Morea A, Mastronardi A, Leante R, Ruggieri M, et al. Diagnostic and prognostic power of CSF Tau in amyotrophic lateral sclerosis. J Neurol. 2018;265:2353-62. https://doi.org/10. 1007/s00415-018-9008-3.

32. Paladino P, Valentino F, Piccoli T, Piccoli F, La Bella V. Cerebrospinal fluid tau protein is not a biological marker in amyotrophic lateral sclerosis. Eur J Neurol. 2009;16:257-61. https://doi.org/ 10.1111/j.1468-1331.2008.02405.x.

33. Pijnenburg YAL, Verwey NA, van der Flier WM, Scheltens P, Teunissen CE. Discriminative and prognostic potential of cerebrospinal fluid PhosphoTau/Tau ratio and neurofilaments for frontotemporal dementia subtypes. Alzheimers Dement Amst Neth. 2015;1:505-12. https://doi.org/10.1016/j.dadm.2015.11.001.

34. Walter MC, Wenninger S, Thiele S, Stauber J, Hiebeler M, Greckl E, Stahl K, Pechmann A, Lochmüller H, Kirschner J, et al. Safety and treatment effects of nusinersen in longstanding adult 5q-SMA type 3-a prospective observational study. J Neuromuscul Dis. 2019;6:453-65. https://doi.org/10.3233/JND-190416.

35. Wurster CD, Koch JC, Cordts I, Dreyhaupt J, Otto M, Uzelac Z, Witzel S, Winter B, Kocak T, Schocke M, et al. Routine cerebrospinal fluid (CSF) parameters in patients with spinal muscular atrophy (SMA) treated with nusinersen. Front Neurol. 2019. https://doi.org/10.3389/fneur.2019.01179.

36. Müschen LH, Osmanovic A, Binz C, Jendretzky KF, Ranxha G, Bronzlik P, Abu-Fares O, Wiehler F, Möhn N, Hümmert MW, et al. Cerebrospinal fluid parameters in antisense oligonucleotidetreated adult 5q-spinal muscular atrophy patients. Brain Sci. 2021. https://doi.org/10.3390/brainsci11030296.
37. Singh NN, Hoffman S, Reddi PP, Singh RN. Spinal muscular atrophy: broad disease spectrum and sex-specific phenotypes. Biochim Biophys Acta Mol Basis Dis. 2021;1867: 166063. https:// doi.org/10.1016/j.bbadis.2020.166063.

38. Shababi M, Habibi J, Yang HT, Vale SM, Sewell WA, Lorson CL. Cardiac defects contribute to the pathology of spinal muscular atrophy models. Hum Mol Genet. 2010;19:4059-71. https://doi. org/10.1093/hmg/ddq329.

39. Khairallah M-T, Astroski J, Custer SK, Androphy EJ, Franklin CL, Lorson CL. SMN deficiency negatively impacts red pulp macrophages and spleen development in mouse models of spinal muscular atrophy. Hum Mol Genet. 2017;26:932-41. https://doi. org/10.1093/hmg/ddx008.

40. Deguise M-O, Kothary R. New insights into SMA pathogenesis: immune dysfunction and neuroinflammation. Ann Clin Transl Neurol. 2017;4:522-30. https://doi.org/10.1002/acn3.423.

41. Wan B, Feng P, Guan Z, Sheng L, Liu Z, Hua Y. A severe mouse model of spinal muscular atrophy develops early systemic inflammation. Hum Mol Genet. 2018;27:4061-76. https://doi.org/10. 1093/hmg/ddy300.

42. Zeman A, McLean B, Keir G, Luxton R, Sharief M, Thompson E. The significance of serum oligoclonal bands in neurological diseases. J Neurol Neurosurg Psychiatry. 1993;56:32-5.

43. Gingele S, Hümmert MW, Alvermann S, Jendretzky KF, Bönig L, Brieskorn M, Schwenkenbecher P, Sühs K-W, Müschen LH, Osmanovic A, et al. Routine cerebrospinal fluid cytology reveals unique inclusions in macrophages during treatment with nusinersen. Front Neurol. 2019;10:735. https://doi.org/10.3389/fneur. 2019.00735 .

44. Machacek ME, Gogakos T, Fletcher MC, Lunderville KA, Swoboda KJ, Sohani AR. Unusual inclusions in cerebrospinal fluid macrophages of spinal muscular atrophy patients treated with nusinersen. Int J Lab Hematol. 2020. https://doi.org/10.1111/ijlh. 13392.

45. Frazier KS. Antisense oligonucleotide therapies: the promise and the challenges from a toxicologic pathologist's perspective. Toxicol Pathol. 2015;43:78-89. https://doi.org/10.1177/0192623314 551840.

46. Hartmann G, Krug A, Waller-Fontaine K, Endres S. Oligodeoxynucleotides enhance lipopolysaccharide-stimulated synthesis of tumor necrosis factor: dependence on phosphorothioate modification and reversal by heparin. Mol Med. 1996;2:429-38.

47. Schoch KM, Miller TM. Antisense oligonucleotides: translation from mouse models to human neurodegenerative diseases. Neuron. 2017;94:1056-70. https://doi.org/10.1016/j.neuron.2017.04. 010.

48. Freigang M, Wurster CD, Hagenacker T, Stolte B, Weiler M, Kamm C, Schreiber-Katz O, Osmanovic A, Petri S, Kowski A, et al. Serum creatine kinase and creatinine in adult spinal muscular atrophy under nusinersen treatment. Ann Clin Transl Neurol. 2021. https://doi.org/10.1002/acn3.51340. 


\section{Authors and Affiliations}

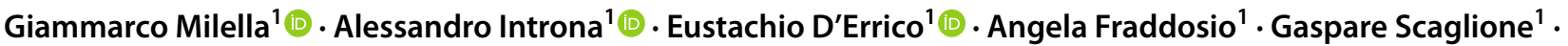
Antonella Morea ${ }^{1} \cdot$ Maria Ucci $^{1} \cdot$ Maddalena Ruggieri $^{2}(1) \cdot$ Mariangela Mastrapasqua $^{2} \cdot$ Marisa Megna $^{3}(1) \cdot$

Filomena Puntillo ${ }^{4}\left(\mathbb{D} \cdot\right.$ Isabella Laura Simone ${ }^{1}(\mathbb{0}$

1 Neurology Unit, Department of Basic Medical Sciences, Neurosciences and Sense Organs, University of Bari "Aldo Moro", Piazza Giulio Cesare 11, 70124 Bari, Italy

2 Neurophysiopathology Unit, Department of Basic Medical Sciences, Neurosciences and Sense Organs, University of Bari “Aldo Moro", Bari, Italy
3 Physical Medicine and Rehabilitation Unit, Department of Basic Medical Sciences, Neurosciences and Sense Organs, University of Bari "Aldo Moro", Bari, Italy

4 Anesthesia, Intensive Care, and Pain Unit, Department of Interdisciplinary Medicine (DIM), University of Bari "Aldo Moro", Bari, Italy 